\title{
Problemer med å måle eksponering for passiv røyking blant barn
}

\author{
Per Nafstad, Grete Botten og Per Magnus \\ Seksjon for epidemiologi, Statens Institutt for Folkehelse, Postboks 4404 Torshov, 0403 Oslo \\ Korrespondanse til Per Nafstad, Telefon 220422 00, telefax 22042351
}

\begin{abstract}
SAMMENDRAG
Vanligvis måles eksponering for passiv røyking blant barn ved spørreskjemaopplysninger om foreldres røykevaner. Etter hvert som det blir mer oppmerksomhet om helseeffekter av passiv røyking, vil det kunne påvirke hvordan foreldre røyker og dermed også barns eksponering. Med henvisning til innsamlede data om røykeeksponering i en kohort av Oslo-barn og fra en studie av barn ved to helsestasjoner, diskuteres noen av de metodeproblemene en står overfor når en skal måle eksponering for passiv røyking i epidemiologiske studier. I disse studiene er barns eksponering for passiv røyking målt ved spørreskjemaopplysninger og ved måling av hårnikotin og kotinin i urin. Det konkluderes med at det er usikkerhet om nøyaktigheten av eksisterende metoder for måling av passiv røyking. Dette og manglende kunnskap om faktisk eksponeringsnivå kan føre til feilaktig estimering av helseeffekter av passiv røyking i en barnebefolkning.
\end{abstract}

Nafstad P, Botten G, Magnus P. Problems in measuring environmental tobacco smoke exposure in children. Nor J Epidemiol 1995; 5 (2): 141-144.

\section{ENGLISH SUMMARY}

Usually environmental tobacco smoke exposure among children is measuered by questionnaires, recording parental smoking. As the adverse health effects of environmental tobacco smoke exposure are getting more known among the public, this is likely to influence the parents' way of smoking and by that their children's actual exposure. With references to findings in a cohort study of Oslo children and a study of children attending two of Oslo's health centers, some methodological problems when measuring environmental tobacco smoke exposure in epidemiological studies are discussed. The exposure in these studies is measured in questionnaires to the parents and as children's hair nicotine concentration and urine cotinine concentration. Furthermore, the paper discusses how the uncertainty in actual levels of exposure may lead to false estimates for the total health impact of environmental tobacco smoke exposure in a population of children.

\section{INNLEDNING}

En rekke publikasjoner har vist at passiv røyking er assosiert til økt risiko for flere sykdommer og symptomer. De fleste av undersøkelsene om helseeffekter av passiv røyking hos barn er referert i Environmental Protection Agency's rapport om passiv røyking fra 1992 (1). Det har på grunnlag av resultater fra disse undersøkelsene blant annet blitt beregnet antallet barn i USA som hvert år vil få nedre luftveisinfeksjoner og antall barn som vil få utløst sin astma på grunn av passiv røyking. Det poengteres at det er stor usikker- het $\mathrm{i}$ disse beregningene blant annet på grunn av usikkerhet om nøyaktigheten av eksponeringsmålingene. Til tross for den store betydningen passiv røyking har blitt tillagt i Norge, finnes det lite dokumentasjon av helseeffekter av passiv røyking blant barn fra norske undersøkelser (2-4). Vurdering av helseeffektene må derfor i stor grad bli basert på resultater av forskning $i$ andre land. Hensikten med denne artikkelen er å diskutere noen av de problemene vi mener vi står overfor ved vurderinger av barns helseeffekter av passiv røyking. Diskusjonen er delvis basert på resultater av innsamlede data om eksponering for 
tobakksrøyk blant små barn (publiserte og upubliserte) foretatt ved Folkehelsa i perioden 1992-95. Noen av resultatene blir summarisk presentert for å belyse problemene med usikre eksponeringsmålinger.

\section{EKSEMPLER FRA EGNE EKSPONERINGSMÅLINGER}

1. Spørreskjemaopplysninger om 0-2 år gamle barns røykeeksponering har vært samlet inn i en kohort av 3754 barn født i 1992/93 (5). Av foreldrene til barna i fødselskohorten fra 1992/93 røykte $27 \%$ av mødrene og $37 \%$ av fedrene da barna var 6 måneder gamle (manglende opplysninger for 207 mødre og 304 fedre). Ca 30\% av røykerne oppga at de røykte av og til, men ikke daglig og 5\% av mødre og $13 \%$ av fedre oppga at de røykte 15 eller flere sigaretter per dag. Av de tilsammen 1596 barna med fedre og/eller mødre som var røykere, bodde $50 \%$ i hjem hvor det ble oppgitt at det ikke ble røykt innendørs.

2. For å validere spørreskjemaopplysninger om røyking ble hårnikotinnivået målt hos 157 1-2 år gamle barn fra kohorten født i 1992/93. Disse barna var deltagere i en "nested" case-control studie med formål å studere risikofaktorer for obstruktive lungesymptomer. Hårprøvene ble tatt under besøk i barnas hjem (5). Prøvetakings- og analyseprosedyrer er beskrevet av Zahlsen og Nilsen (6). Foreløpige analyser viser at median hårnikotinkonsentrasjon blant barn av ikkerøykende mødre og ikkerøykende fedre $(n=84)$ var (25-75 percentiler $i$ parenteser) 1.1 $\mu \mathrm{g} / \mathrm{g}(0.4-1.6)$, av ikkerøykende mødre og røykende fedre $(\mathrm{n}=17) 2.1 \mu \mathrm{g} / \mathrm{g}(1.0-4.4)$, av av og til røykende mødre $(n=14) 3.4 \mu \mathrm{g} / \mathrm{g}$ (2.1-6.2), av mødre som røykte 1-9 sigaretter per dag $(\mathrm{n}=15) 2.6 \mu \mathrm{g} / \mathrm{g}(0.9-3.5)$ og av mødre som røykte 10 eller flere sigaretter per dag $(\mathrm{n}=24) 3.9 \mu \mathrm{g} / \mathrm{g}(2.1-12.9)$ (ufullstendige røykeopplysninger for tre barn). Median hårnikotinkonsentrasjon hos barn fra hjem hvor det ble røykt innendørs $(\mathrm{n}=41)$ var $4.1 \mu \mathrm{g} / \mathrm{g}(2.1-9.4)$, i hjem hvor det ikke ble røykt innendørs $(\mathrm{n}=116) 1.2 \mu \mathrm{g} / \mathrm{g}(0.7-2.7)$. Økende utdanningsnivå $\mathrm{i}$ familien førte til et redusert hårnikotinnivå hos barna, også når foreldres røykevaner og innendørs røyking var kontrollert for (Tabell 1).

3. Hårnikotinnivået og kotininnivået $\mathrm{i}$ urin har blitt målt hos 94 12-36 måneder gamle barn og deres mødre rekruttert fra to helsestasjoner i Oslo (7). På grunn av utilstrekkelig størrelse på hårprøve mangler hårnikotinkonsentrasjonen for en mor og ett barn. Det ble funnet nikotin i hår og kotinin i urin i alle analyserte hår- og urinprøver, også fra de barn som kom fra hjem uten røykende foreldre. Fra det samme datamaterialet viste hårnikotinmålingene (både hos mor og barn) økende verdier ved økende konsum av sigaretter, men det var stor spredning (Figur 1). Median hårnikotinkonsentrasjon blant barn av røykende mødre var $5.0 \mu \mathrm{g} / \mathrm{g}$ (25-75 percentil: 2.1- 10.1), og blant barn av ikkerøykende mødre $1.7 \mu \mathrm{g} / \mathrm{g}(0.7-3.9)$.

Tabell 1. Determinanter for hårnikotinkonsentrasjon $(\mu \mathrm{g} / \mathrm{g})^{*}$ hos barn i alderen 1-2 år (multippel lineær regresjon).

\begin{tabular}{lcc}
\hline Passiv røyking & Beta-koeffisient & 95\% konfidensintervall \\
\hline Mor ikke-røyker/ far ikke-røyker & ref & \\
Mor ikke-røyker/ far røyker & 0.43 & $-0.07-0.92$ \\
Mor røyker av og til (ikke daglig) & 0.56 & $0.03-1.10$ \\
Mor røyker daglig & 0.45 & $0.03-0.87$ \\
Røyking inne i barnets hjem (ja/nei) & 0.71 & $0.31-1.11$ \\
Kjønn (jenter/gutter) & 0.35 & $0.07-0.64$ \\
Mors utdanning & & \\
$\quad<12$ år & ref & \\
$\quad 12-15$ år & -0.31 & $-0.93-0.30$ \\
$\quad>15$ år & -0.64 & $-1.31--0.03$ \\
Fars utdanning & & \\
$\quad<12$ år & ref & \\
$12-15$ år & -0.58 & $-1.06--0.01$ \\
$\quad>15$ år & -0.78 & $-1.31--0.25$ \\
\hline
\end{tabular}

Forklart varians: $\mathrm{R}^{2}=0.37$

ref: referansekategori

*: logaritmetransformerte hårnikotinkonsentrasjoner

$\AA$ ha hatt astmaliknende plager bidro ikke signifikant i den lineære regresjonsmodellen. 


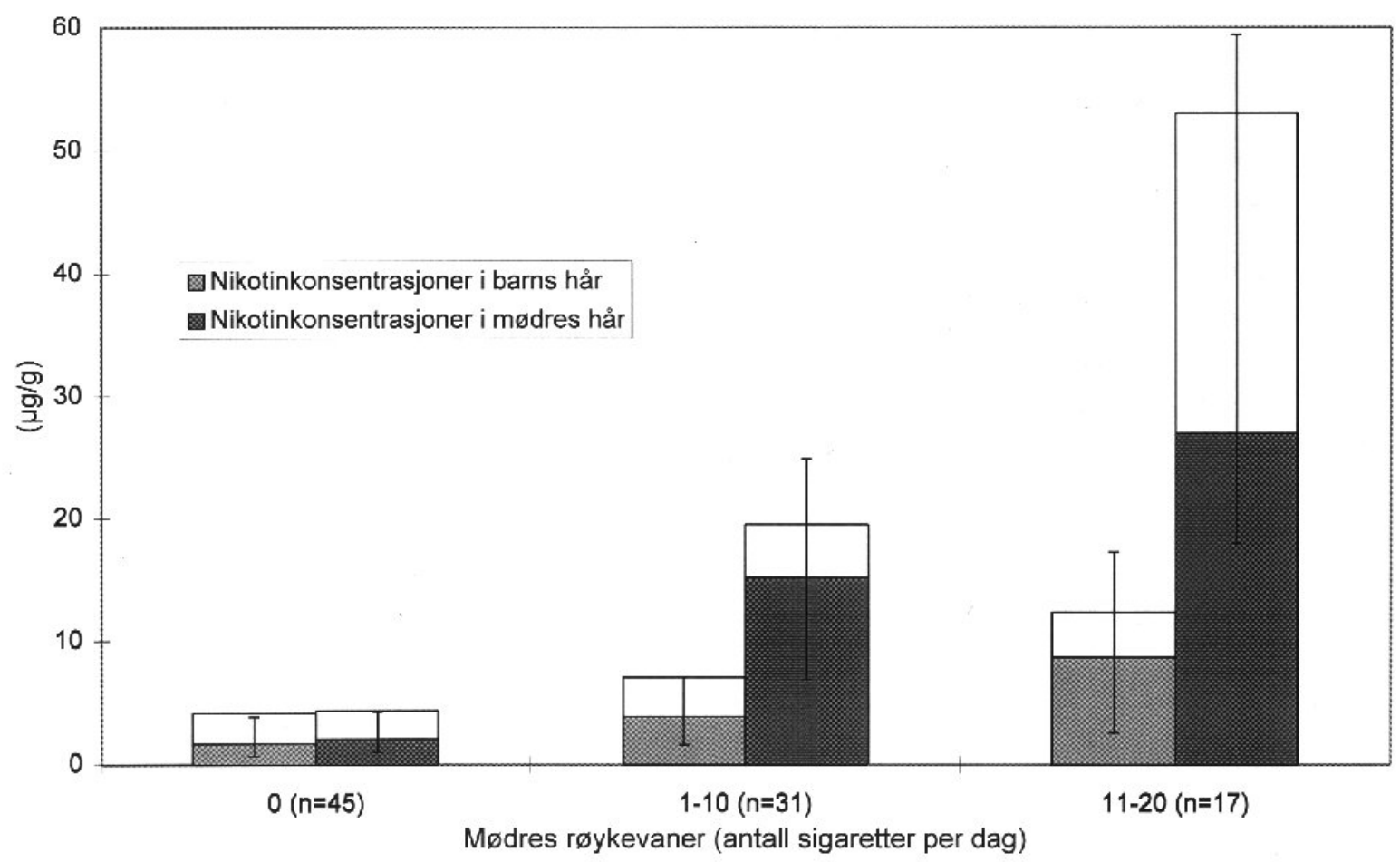

Figur 1. Hårnikotinverdier $(\mu \mathrm{g} / \mathrm{g})$ hos 94 barn og deres mødre etter daglig antall sigaretter moren røyker. Median (kompakte del av søylene), gjennomsnitt (kompakt + åpen del av søylene) og 25-75 percentil (feilintervallene). Utilstrekkelige hårprøver fra en mor og hennes barn.

\section{DISKUSJON}

Eksemplene referert overfor tyder på stor variasjon i nikotinmengde $\mathrm{i}$ hår hos barn med foreldre med like røykevaner og at mange foreldre forsøker å redusere barnas eksponering for passiv røyking.

Presise eksponeringsmål er vesentlig for å måle helseeffekter av passiv røyking. Environmental Protection Agency poengterer også dette (1). De fleste studier av helseeffekter av passiv røyking har vært basert på spørreskjemaopplysninger som mål for passiv røyking. Dette forutsetter valide røykeopplysninger fra personer i omgivelsene. Det forutsetter også at omgivelsespersoners røykevaner er et godt mål for en persons faktiske eksponering. Dette kan sjelden dokumenteres, men antas ofte selv om det synes klart at forhold som ventilasjon, avstand mellom forurensningskilde og den eksponerte og varighet av eksponering må virke inn på eksponeringsgraden. Det synes rimelig å anta at omgivelsespersoners røykevaner var et bedre mål for passiv røyking den gang helseeffektene av passiv røyking var lite kjent. Effekten av økt kunnskap om passiv røyking og røykelov har sannsynligvis redusert nøyaktigheten av omgivelsespersoners røykevaner som mål for en persons eksponering for passiv røyking. Det kan også ha ført til redusert eksponering. Økt risiko for røykerelaterte sykdommer har vesentlig vært vist for høyeksponerte barn. Dermed er kjennskap til andelen høyeksponerte barn i en befolkning vesentlig for å kunne estimere helseeffekter av passiv røyking. Så vidt vi vet er det få nyere norske undersøkelser om småbarnsforeldres røykevaner. Resultatene fra barnekohorten fra 1992/93 kan tyde på at det er få småbarnsforeldre som røyker mye nå for tiden. Det tyder også på at røykende foreldre gjør tiltak for å redusere barnas tobakksrøykeksponering og at evnen til å gjennomføre dette, øker med utdannelsesnivået. En persons eksponering for passiv røyking målt som omgivelsespersoners røykevaner og målt som personens hårnikotinnivå vil i mange tilfeller bli forskjellig. Siden det ikke finnes noen gullstandard for måling av røykeeksponering kan dette tolkes på flere måter. En rimelig tolkning ville være at resultatene demonstrerer usikkerheten $\mathrm{i}$ å måle en persons eksponering for passiv røyking ved hjelp av omgivelsespersoners røykevaner. Andre studier med målinger av tobakksrøykprodukter i luft eller i kroppsvæsker kan tolkes i samme retning (8-11). Resultatene av kotininmålinger i urin og nikotinmålinger i hår tyder på at det er vanlig å ha vært eksponert for noe nikotin selv om det ikke finnes røykere i omgivelsene. Dette antyder at det ikke er en ikke-eksponert gruppe en sammenligner med når barn med røykende foreldre sammenlignes med barn av ikke-røykende foreldre.

En forutsetning for å kunne applisere risiko for helseeffekter av passiv røyking fra andre land på norske barn er at man har sammenlignbare ekspone- 
ringsnivåer. Det er flere forhold som gjør det usikkert å anta at samme sigarettkonsum vil gi samme nivå av eksponering for passiv røyking i Norge og i andre land (forskjeller i klima (i Norge mye inneliv), livsstil, kunnskapsnivå, opplysningsarbeid om skadelige helseeffekter av passiv røyking, barnepassordninger og regulering av røyking (røykelover)). Mangel på gode metoder for å måle passiv røyking gjør sammenligninger av eksponeringsnivå i forskjellige studier usikre. Hårnikotinmålinger kan være en metode som forbedrer muligheten til slike sammenligninger, men foreløpig er det få studier som har benyttet metoden (12-14).

Spørreskjemaopplysninger om omgivelsespersoners røykevaner kan i beste fall være et grovt mål for en persons eksponering for passiv røyking. Økt oppmerksomhet om helseeffekter av passiv røyking svekker antakelig relasjonen mellom omgivelsespersoners røykevaner og en persons faktiske eksponering for passiv røyking. Dette vil stille stigende krav til design og eksponeringsmåling hvis en ønsker å studere helseeffekter av passiv røyking i framtiden.

\section{REFERANSER}

1. Respiratory Health Effects of Passive Smoking: Lung Cancer and Other Disorders. United States Environmental Protection Agency. EPA/600\6-90\006F. Washington, DC, 1992.

2. Søyseth V, Kongerud J, Boe J. Postnatal maternal smoking increases the prevalence of asthma but not of bronchial hyperresponsiveness or atopy in their children. Chest 1995; 107: 389-94.

3. Carlsen KH, Larsen S, Bjerve Ø, Leegaard J. Acute bronchiolitis. Predisposing factors and characterization of infants at risk. Pediatr Pulmonol 1987; 3: 153-60.

4. Nafstad P, Kongerud J, Hagen JA, Botten G. Passiv røyking og nedre luftveisinfeksjoner blant små barn. Er det en sammenheng også i Norge? Norsk Epidemiologi 1995; 5: 50-4.

5. Nafstad P, Øie L, Kongerud J, Botten G. Exposure assessments in the Oslo Environment and Childhood Asthma Study. Proceedings of Indoor Air'93; 1: 809-14.

6. Zahlsen K, Nilsen OG. Nicotine in hair of smokers and non-smokers. Sampling procedure and gas chromatographic/mass spectrometric analysis. Pharmacol Toxicol 1994; 74: 143-9.

7. Nafstad P, Botten G, Hagen JA, Zahlsen K, Nilsen OG, Silsand T, Kongerud J. Comparison of three methods for estimating environmental tobacco smoke exposure among children aged between 12 and 36 months. Int J Epidemiol 1995; 24: 88-94.

8. Coultas DB, Howard CA, Peaks GT, et al. Salivary cotinine levels and involuntary tobacco smoke exposure in children and adults in New Mexico. Am Rev Respir Dis 1987; 136: 305-9.

9. Coultas DB, Samet J, McCarthy JF, Spengler JD. Variability of measures of exposure to environmental tobacco smoke in home. Am Rev Respir Dis 1990; 142: 602-6.

10. Delfino RJ, Ernst P, Jaakkola S, Becklake MR. Questionnaire assessments of recent exposure to environmental tobacco smoke in relation to salivary cotinine. Eur Respir $J$ 1993; 6: 1104-8.

11. Marbury MC, Hammond SK, Haley NJ. Measuring exposure to environmental tobacco smoke in studies of acute health effects. Am J Epidemiol 1993; 137: 1089-97.

12. Kintz P. Gas chromatographic analysis of nicotine and cotinine in hair. J Chromatogr 1992; 580: 347-353.

13. Li Y, Cheng L. Analysis of nicotine in hair as a biological marker for ETS exposure. Proceedings of Indoor Air'93; Vol.1: 687-92.

14. Eliopoulos C, Klein J, Khanh Phan M, Knie B, Greenwald M, Chitayat D, Koren G. Hair concentrations of nicotine and cotinine in women and their newborn infants. JAMA 1994; 271: 621-63. 